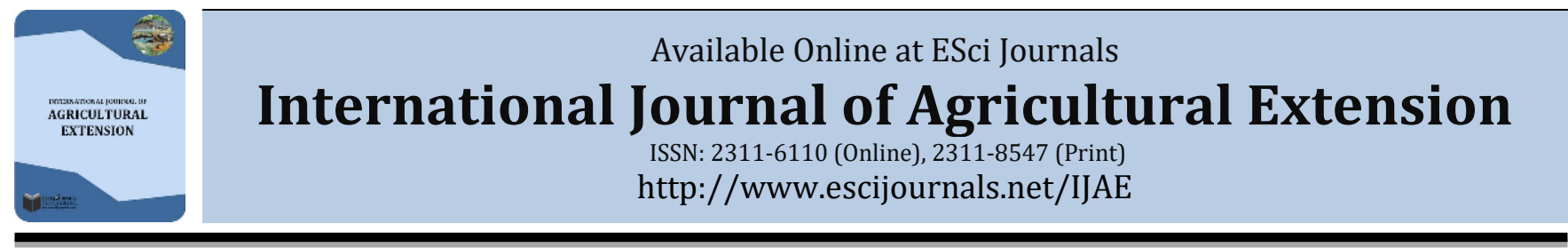

\title{
ANALYSIS OF IMPROVED INDIGENOUS CHICKEN ADOPTION AMONG SMALLHOLDER FARMERS: CASE OF MAKUENI AND KAKAMEGA COUNTIES, KENYA
}

\author{
aChristopher N. Kamau *, bucy W. Kabuage, aEric K. Bett \\ ${ }^{a}$ College a Department of Animal Science Kenyatta University, Narobi, Kenya. \\ ${ }^{b}$ Department of Agricultural Economics. Kenyatta University, Narobi, Kenya.
}

\section{A B S T R A C T}

Indigenous chicken (IC) production is a source of food security and income among smallholder farmers within high potential areas and semi-arid lands (ASAL). The demand for IC eggs and meat is anticipated to increase threefold by the year 2020 by health conscious consumers. However, potential of IC to contribute to household incomes and poverty alleviation in ASAL is constrained by slow maturity of IC and low productivity. Hence, to address these constraints improved indigenous chicken (IIC) technologies have been developed and introduced to smallholders in high potential area and ASAL. However, only a few smallholder farmers have adopted the IIC technologies. Therefore, the objective of this study was to determine the effect of farmer socioeconomic characteristics on adoption and intensity of adoption the IIC technology in Makueni and Kakamega counties. A total of 384 households were sampled using multi-stage sampling to collect data through interviews. The collected data was analysed using a double hurdle model. The results suggest that sex of the household head, farm size, group membership, which had not been previously identified in IIC studies as a significant variable, distance to training centre, off-farm activities and IIC awareness significantly affected adoption decision of improved IC. On the other hand, education of the household head, household size, farm size, source of information on IIC and awareness on IIC had significant effects on the level of adoption. The recommendations from this study have an implication on extension policy, land use policy, food policy, collective action and pricing policy in the context of technology adoption in Kenya.

Keywords: Adoption, double hurdle, indigenous chicken, membership, training, technology.

\section{INTRODUCTION}

Agriculture contributes to at least $23 \%$ of the gross domestic product (GDP) of Kenya, where production is predominantly done by smallholders (Republic of Kenya (RoK), 2013). The smallholder farmers in Kenya are characterised by subsistence production, which is conducted on fragmented pieces of land that have low productivity. These pieces of land are used to produce local crop varieties and animal breeds despite the existence of new improved crop varieties and animal breeds. However, these smallholder farmers are projected to contribute a significant proportion of the agricultural products for subsistence consumption. The smallholder farmers account for $80 \%$ of the total national poultry production in Kenya (MoLFD, 2011).

* Corresponding Author:

Email: chricat89@gmail.com

(C) 2019 ESci Journals Publishing. All rights reserved.
These smallholder farmers in developing countries are characterized by low productivity, low incomes and incidences of food insecurity compared to other farmers in the world (Kidanemariam et al., 2013). The rearing of IC provides wealth and food security to at least $80 \%$ of households in developing countries and consequently alleviates poverty and malnutrition menace (Moreki et al., 2010; Okello et al., 2010; Sadya, 2012). Moreover, rearing of IC is estimated to contribute $30 \%$ of white meat in the world, whereas in Kenya, it accounts for $47 \%$ of eggs and 55\% of meat respectively (FAO 2012; Kingori et al., 2010). Adoption of improved indigenous chicken (IIC) breeds has the potential of transforming livelihoods of populations in the developing countries of the world. There has been an increase in the demand for white meat and its related product in the past decade coupled with a growth in population, urbanization and an increase in per capita disposable income (USAID, 
2010). Further, there exists unmet demand for the IC products in most of the urban and peri urban areas of the countries where smallholders are found (WSPA, 2012). Moreover, the health conscious consumers have a preference for IC meat which they perceive to be lean, nutritious, tasty and good flavour (King'ori et al., 2010). Thus, consumers are willing to pay a premium prices for IC meat and eggs (Bett et al., 2011). Therefore, despite the existence of the IC markets the IC production levels among the smallholder farmers remains low.

The production of IC is mainly done under free range system by smallholder farmers who are constrained by resources (Aboki et al., 2013). This free range production system exposes the IC to different contaminated feeds, which are a potential source of diseases for IC. Furthermore, smallholder farmer experience loss of IC to predators and uncollected eggs in open fields. The spread of poultry diseases are rampant in the free range system, where IC frequently interacts and may lead to loss of flocks (Yitbarek et al., 2013).

IC farmers have difficulties in accessing quality inputs for production and rely on improvised technology or in most cases do not incorporate technology in their production systems (Awuni, 2003; FAO, ECTAD, 2009). These inputs include the access to veterinary services and adequate number of IC chicks, which the farmers accessed from Government before privatization of extension services. The consequence is that IC farmers have inadequate skills on the production of IC for commercial purpose, which confines most smallholder farmers to subsistence production (Hossen, 2010).

Moreover, these smallholder farmers are not competitive enough compared to the exotic chicken producers, who have a commercialised operation system (Menge et al., 2005; FAO, 2012; King'ori et al., 2010). The intermittent production means that few of the smallholders are unable to supply IC constantly to the markets in the urban and peri urban areas in Kenya (Kahi et al., 2012; Kandia, \& Kitalyi, 2002). Further, IC farmers experience losses of IC from diseases and physical injuries during transportation to distant markets (Bwalya \& Thomson, 2014).

Climate change has led to an increase in arid lands area and an alteration in systems of production used in agriculture within the world, which in turn has an effect on smallholder livelihoods. Livestock production has been adopted in most arid areas as a coping mechanism and as a source of incomes and food security in arid lands. Therefore, most households in the arid and semiarid lands rear indigenous livestock breeds including cattle, camel, donkeys and poultry. However, crop production in these lands is constrained by water scarcity and resource constraints among smallhoder, which leads most households to adopt livestock for food security, incomes, draught power and insurance. Moreover, IC forms the ground for acquisition of other herds of livestock for the resource poor households (Moreki \& Dikeme, 2011).

Indigenous chicken is preferred in most of the households in the arid and semi-arid areas in developing countries like Kenya. Smallholder farmers prefer IC to other types of chicken due to disease resistance, adoptability to arid climates, their ability to utilize low quality feeds and diverse IC markets (Mengesha, 2012). Further, IC is hardy, good adapters and survives well in harsh conditions of feed fluctuations with a low cost of production (King'ori et al., 2010). Hence, IC production is mainly done for subsistence use by smallholder farmers with a few commercial producers, who have adopted IIC (Okello et al., 2010). On the other hand, the production of exotic chicken is mainly commercial with large scale production and good market links (Kandia \& Kitalyi, 2002).

Erratic climate changes have exacerbated food security in Africa at large and particularly in Kenya, where households in arid and semi-arid lands are exposed to food insecurity (GOK, 2007). Consequently, the ecological conditions surrounding most of the smallholder farmers hinder optimal or maximum production from arid and semi-arid lands (Aboki et al., 2013). The smallholders in the Arid and Semi-Arid Lands (ASALs) may require coping mechanism such as irrigation facilities or adoption of improved chicken breeds to increase production (Adomako et al., 2010). Consequently, the adoption of improved crop variety and animal breeds is expected to result into improved incomes and food security in households (Kummar et al., 2013). However most of these smallholder farmers have not adopted the IIC which are adoptable to ASAL areas and have a higher production compared to the IC.

As highlighted so far, Indigenous chicken have numerous benefits associated with health benefits, adaptation to harsh environments, easy conversion to cash, which act as insurance for smallholder households. However, a key draw back in the production and marketing of IC is the 
long maturity period of 2 to 3 years. On the other hand, the exotic chickens are characterised by shorter maturity periods of at least 4 months, which is an attractive marketing attribute. Consequently, research in poultry farms has led to cross breeds between indigenous and exotic breeds, which have shorter maturity periods. These cross breeds or IIC are able to adapt to the arid and semi-arid areas, while offering potential for income and food security for households in these locations.

The other challenge in the production of IC is related to the production levels among the smallholder farmers in Kenya. This low production is majorly related to the small flock sizes, which are average of 5 chickens that may take long periods to attain full maturity. Another factor that contributes to small flock sizes are the high mortality rates among chicks as a result of bio safety and bio hazards in arid environments. Smallholder farmers in arid and semi-arid lands use indigenous knowledge in rearing of IC in the households. This knowledge ranges from production of feeds, brooding of chicks, and housing of chicken and disease management. However, this knowledge may not be efficient in the production of IIC or may be obsolete in some instances. Moreover, most extension services may not contain adequate information on the animal husbandry related to IIC in Kenya. Consequently, smallholder farmers resort to innovations or resort back to indigenous knowledge for the production of IIC.

A wide range of interventions, targeting households, have emerged to address the challenges in the production of IC. First, IIC breeds, which have desirable traits, including hardiness, high productivity, palatability and disease tolerance, have been developed for better production in ASAL areas (Kahi et al., 2012; KARI, 2011; Magothe et al., 2012). Second the smallholder farmers have received training on IC production to supplement on other sources of knowledge and boost production of IC in ASAL areas in Kenya (King'ori et al., 2010). Third, most of the IC farmers have been trained on feed formulation and rationing with essential nutrients to improve on the production of IC (Magothe et al., 2012). Thus, the advocated interventions to improve IC productivity include improved genotype, feed supplementation, vaccination and improved rearing system (Njue et al., 2006; Ochieng et al., 2011). Adoption of production technologies result to positive margins along the value chain and thus constraints affecting IC needs to be addressed (Yitbarek, 2013).

ASAL are conducive for the production of IC based on some inherent advantages conferred by the environment factors and economic factors (Abreha, 2007). Moreover, exotic breeds are unlikely to survive the harsh ASAL environments which lead to suboptimal performance (Kingori et al., 2010). The IC production is a low labour enterprise, which makes it a suitable enterprise among resource constrained households' smallholder in ASAL areas (Zeberga, 2010). The IC production in ASAL is favoured by suitable range of climatic conditions. Moreover, ASAL areas have a wide diversity of flora and fauna that facilitate the production of IC from minimum resources and inputs (Magothe et al., 2012). The effective food conversion ratio of IC makes them suitable for production in the ASAL areas, where the production of feeds is constrained by terrain. Despite the inherent competitive advantage in the production of IC, few households have adopted the IIC technologies in these ASAL areas.

The current adoption rate of improved technologies among smallholder farmers in ASALs is low despite significant investments in these technologies (Kingori et al., 2010). For instance, in Kenya average adoption rate of IIC technologies is estimated at $24 \%$ among smallholders' despite the awareness that has been generated around the IIC technologies (Ochieng et al., 2011). The smallholders still produce small IC flock sizes under free range systems despite the introduction of improved housing technologies for IC, which are meant to house the IC for bio safety. In addition, incidences of contaminated IC carcass and physical injuries on IC are still reported at major market terminals. This scenario occurs despite the introduction of transportation crates that aim at reducing injuries and disease spread of IC in the market. The smallholder farmers in the ASAL predominantly feed their IC on a range of natural materials that are found in the free range system (Ectad (FAO), 2009). Moreover, there are a limited number of smallholder farmers that formulate their feeds locally as evidenced by large quantity of feeds from outside ASAL areas in Kenya. However, a significant amount of resources have been used in information dissemination among smallholder farmers on good IC feeding practices through trainings, media, field days and agricultural shows (Ezezika et al., 2012). 
IC has a critical role in agriculture within developing countries such as Kenya and contributes significantly to food security, income generation and improved health status among smallholders (Awuni, 2003; Mapiye et al., 2008). The IC is a preferred intervention strategy for poverty alleviation and food security among smallholder households in ASAL areas. The main constraint in the production of IC is the small flock sizes with long maturity period (Thiruvenkadan et al., 2013). On the other hand, inventions have been developed to address these challenges in the production of IC. However, the numbers of smallholders who adapt these IIC are low despite significant interventions and investments. This improved productivity on IC will result to increased income among the smallholder farmers hence spearheading to achievement of millennium development goals (ROK, 2010). Consequently, smallholders are exposed to a viscous poverty cycle despite the existence of a viable exit strategy in the form of IIC Consequently, it is on this basis that the present study was conducted to analyse the determinants of adopting IIC in Makueni and Kakamega counties.

Adoption of improved agricultural technologies: a review: There is an abundance of literature on the adoption of technologies by smallholder farmers in the world. The adoption of technologies has been aimed at increasing the production levels of smallholder farmers and consequently improving on their livelihoods. The introduction of agricultural technologies is targeted at the crop and animal production. In this section we present some of the studies that were done on technology adoption in the developing countries.

Adoption of technologies can be viewed as the result of decisions made by an adopter due to the influence of the internal and external environment of an adopter. For example, (Asrat et al., 2010) showed the influence of environment and production characteristics on adoption of technologies. However, gauging the real impact of environment on decision may be based on assuming the effects of other variables. Hence the study applied a perception as the basis of assessment. The perception of an individual may be biased and may result in some cautious conclusions. Therefore, an inbuilt mechanism in the model of analysis and captured in the error terms of the regressions may help account for these biases.

There is a concurrence in literature on adoption that adoption is a sequential process as opposed to a simultaneous event. The process of adoption is characterized by the decision stage that is followed by the intensity stage (Adesina \& Zinnah, 1993). Therefore, a smallholder farmer may consider the specific attributes of the technology first the outcome of which is manifested in the intensity of adoption (Adesina \& Zinnah, 1993). Therefore, the choices that a smallholder will make in relation to adopting new technologies that will bring minimal disruption to environment and yields. Further smallholder socioeconomic characteristics such as asset endowments (livestock owned), contact with extension and years of experience also influence the decision on adoption of technologies and the intensity of adoption of technologies (Asarat et al., 2010; Ghimire et al., 2015). However, smallholder farmers may have different sources of information and may be located at different distances from centers of training. The effects of these two factors have not been adequately analyzed in literature on technology adoption. Hence our study aimed at analyzing the effects of the same variables on adoption and the intensity of adoption.

A study by (Gillespie et al., 2014) showed that the adoption of new technologies is influenced by socioeconomic characteristics (age, education, farm size and diversification). The relationship between socioeconomic characteristics of farmers and the decision to adopt has been shown in several studies. Moreover, some studies have analyzed the effect of socioeconomic characteristics on intensity of adoption of technology. For example, Ghimire et al., (2014) conducted a study on the adoption of improved rice varieties in central Nepal using a probit analysis. The results showed that the adoption of the improved rice varieties was influenced by education, seed access, land ownership, technology characteristics. Other studies show that the adoption of new technology is influenced by male, number of children in household, region and land (Mendola, 2007). The adopters of technology also consider profits from using the new technology in deciding whether to adopt more of the new technology (Arnholt, 2001). Moreover, a study by Mendola (2007) found that region had a significant influence on the adoption of improved technology. (Muzari et al., 2012) in a review presented the factors that influenced the adoption of technologies as "assets, income, institutions, vulnerability, awareness, labour and innovativeness by smallholder farmers." Despite most studies having done an analysis on the effect of institutions on adoption, few have analyzed effect of participating in institutions such 
as social groups on the adoption of technology and the intensity of the adoption. Hence our study considered social group membership as an important factor in adoption and intensity of adoption of technologies.

Adesina \& Baidu-Forson (1995) analysed the adoption of sorghum varieties in Burkina Faso. The study showed that the adoption of sorghum varieties was significantly influenced by farmers' perception on yield, quality, and adaptability of sorghum to poor soils. The main socioeconomic characteristics that influenced the adoption of sorghum included age of farmer, participation in farm tests and number of times farmer had a contact with extension. (Chi \& Yamada, 2002) analysed the adoption of technologies by farmers in Mekong Delta. The adoption of technologies was favored by Age, education and Male headed households. On the other hand, the adoption of technologies was not favored by older individuals and perception on profitability. The impact of adopted technology on crop productivity is another factor that influence the adoption of technology alongside environmental and biophysical factors (Food and Agriculture Organization(FAO), 2015).Further the adoption of technologies by smallholder farmers may be influenced by availability of information and the influence of neighbours .A study by (Lambert et al., 2015) showed that the adoption of agricultural technologies by farmers was influenced by the scale of operation, access to information and participation in other programs. However, the adoption of technologies e.g. irrigation technologies may be "sensitive" to prices of inputs and cost of technology.

Most studies reviewed here (Adesina \& Zinnah, 1993; Ghimire et al., 2014; Arnholt, 2001) used a probit analysis to analyze adoption of technologies. This is done because the probit model is suited for the analysis of adoption decisions. However, to estimate the intensity may require the estimation of an ordinary least squares (OLS) or a Tobit regression. There are studies (Mendola, 2007) on the other hand that use approaches such as the propensity score matching (PSM) which analyses the impact at the second stage. On the other hand, double hurdle model has been used in studies related to the adoption of poultry technology.

Different studies have analysed the adoption of poultry technology in different countries. For example, Teklewod (2006) analysed the determinants of exotic poultry technology adoption in Ethiopia. However, the focus of this study was on exotic poultry which has been showed to differ from indigenous chicken in terms of consumer preferences (Bett et al., 2011). Further the exotic chicken are kept by commercial poultry farmer and require high capital outlay as compared to IIC that are kept in most households in developing countries (Okello et al., 2010; Ochieng et al., 2011; FAO, 2012). Further the study by Telkwod (2006) focuses on the rate and intensity of adoption, while our study focused on the decision to adopt and the intensity of adoption.

Studies have attempted to evaluate determinants of adopting IIC technology based on different empirical estimations. (Demeke, 2015) characterised animal husbandry systems practices, adoption of technology and impact on indigenous chicken in Ethiopia. This study evaluated a set of technologies related to indigenous chicken namely: feeds, housing, health care and watering needs. Furthermore, training, health care and extension influenced the adoption of improved indigenous chicken. This study used a binary logistic regression to assess determinants of adoption together with a propensity score matching technique. Meanwhile, a study by (Dana, 2011) provided important indicators that household consider in IC breeding in the tropics including low input usage, diseases and predators, dual purpose of chicken for meat and eggs, incomes and occasional morphological traits such as comb colour and shape. (Masha, 2011) analysed the determinants of indigenous technology adoption in Tanzania using multiple range test. The results of the study showed that adoption of technology was significantly influenced by extension, veterinary services and education level of households. A different study by (Lyimo, 2013) on the adoption of improved chicken technology in Tanzania indicated that adoption was significantly influenced by chick mortality rates, capital and feeds. (Sodjinou \& Henningsen, 2012) used a multivariate probit to analyse adoption of improved indigenous poultry technology in Benin.The technology sets that were analysed included vaccines, improved feeds, housing and cockrel breeds. The results show that adoption of improved technologies was significantly influenced by region, gender, education and age of the respondents. (Safalaoh, 2012) evaluated the determinants of adopting chicken breeds through an innovation platform in Malawi. (Wanjugu, 2013) conducted an evaluation of the determinants of IC production in Machakos using a multivariate analysis. The results indicate that the significant factors included disease management and cock management. 
The production of IC has been identified as a viable poverty exit strategy for smallholder farmers. The production of IC does not require a high initial capital and can be done on a small area of land. Second the period of returns on the initial investment for IC is shorter. Third, the production of IC has minimal cost since they can be produced using locally available feeds provided there is bio safety. The production of IC has other products such as eggs, poultry manure, feathers which earn some income for the farmers. Despite the opportunity offered by the adoption of IIC the level of adoption among smallholder farmers remains low. Further most smallholder farmers still live below the poverty line and are faced with food insecurity. Therefore, it was on this basis that the study was conducted with the objective of analyzing the determinants of IIC adoption among small holder farmers in Makueni and Kakamega counties. The rest of this paper is organized as follows: methodology, results and discussions, conclusions and recommendations.

\section{DATA AND ANALYTICAL FRAMEWORK}

Analytical framework: The smallholder farmers make a decision to adopt technology based on the utility that they get from the technology. These smallholder farmers have to maximize on the utility under constraints of budget, inputs and resources that are available to them at a given time. The choices made by the smallholder farmers are made under a random utility framework (Mc Fadden, 2001).

The utility that a smallholder farmer gets from adopting technology can be represented as $U$. The utility of a household that adopts technology can be represented by UAi, while that of a household that does not adopt technology can be shown by UNi.

Hence, a household will decide to adopt the technology if $\mathrm{U}=\mathrm{UAi}-\mathrm{UNi}>0$. The utility adoption will then be modelled as function of the observable characteristics of the ith farmer as shown in equation 1. The utility therefore is the unobservable part of the function.

$\mathrm{U}=\beta \mathrm{X}_{-} \mathrm{i}+\varepsilon_{-} \mathrm{i} \ldots \ldots \ldots \ldots . . . . .1$

Where $\mathrm{U}^{*}$ is a binary variable that represent the decision to adopt a technology and assumes value $\mathrm{U}=1$ for adopters and $\mathrm{U}=0$ otherwise. On the other hand $\mathrm{X}$ is a vector of independent variables to be estimated. While $\beta$ represents the parameter of the variables to be estimated and $\varepsilon$ is the error term. The error term is assumed to have a mean of zero and is normally distributed.
A Double Hurdle approach was used to analyze data. It's a parametric generalization of Tobit model developed by Cragg in 1971. According to Cragg 1971, adoption is faced by 2 tiers; first is whether to adopt or not the technology and secondly is related to level of adoption. The assumption that we made was that the decision to adopt technology and the level of adoption were made in two different steps. The studies on adoption use different empirical models e.g. logit model (Adesina \& Forton, 1995; Gillespie et al., 2014; Asrat et al., 2010) probit model (Ghimire et al., 2015) and dynamic models (Fisher, et al., 2000). The two tiers in the Cragg are represented based on Cragg (1971),

$D^{*} \mathrm{i}=\alpha \mathrm{Zi}+\mathrm{Vi}$ 2

$\mathrm{Y}^{*} \mathrm{I}=\beta \mathrm{Xi}+\mathrm{Ui}$ . .3

Where $\mathrm{Di}=\left\{1\right.$, if $\mathrm{Di}^{*}>0 ; 0$ if $\left.\mathrm{Di}^{*} \leq 0\right\}$ and $\mathrm{Yi}=\left\{\mathrm{Y}^{*}\right.$, if $\mathrm{Y} \mathrm{i}>0$ and $\mathrm{Di}^{*}>0 ; 0$, if otherwise $\}$

$\mathrm{Di}^{*}$ - latent variable that makes the value 1 if the farmer adopts poultry technologies; 0 otherwise, Zi- Vector of household characteristics explaining level of adoption; $\mathrm{Xi}$ - Vector of independent variables explaining the level of adoption (Table 1); Ui and Vi- Stochastic terms which are assumed to be independent.

The two tier model is also referred to us censored regression models. First the models define participation or decision stage by the use of a discrete dependent variable $\left(y^{*}=0, y=1\right)$. The second model is conditional on the result of the first stage. Tobit model assumes that the factors which influence the decision to participate are the same factors that influence the intensity of participation. The assumptions of the Tobit model are relaxed by a double hurdle model that assumes different factors affect the decision of participation/adoption and the level of participation/adoption.

The Cragg model is an example of a double hurdle model that combines a probit model and a function with different distributions. The outcome model is assumed to have a log-normal distribution. However, in the Cragg model the second stage is assumed to have a truncated normal distribution. The truncated distribution contains the Tobit model which allows for the testing of the Tobit hypothesis against the Double hurdle model (Woolridge, 2002). The log likelihood function for the double-hurdle model is expressed as;

$$
\begin{aligned}
& \log L=\sum_{/ 0} \ln \left[1-\phi\left(\alpha Z_{i}^{\prime}\right)\left(\frac{\beta \mathrm{x}_{i}^{\prime}}{\sigma}\right)\right]+ \\
& \sum_{/+} \ln \left[\phi\left(\alpha Z_{i}^{\prime}\right) \frac{1}{\sigma} \varphi\left(\frac{Y_{i-} \beta X_{i}^{\prime}}{\sigma}\right)\right] \ldots \ldots \ldots \ldots . . .4
\end{aligned}
$$

Where $\Sigma / 0$ = summation over the zero observations; $\Sigma /+$ 
stands for summation over positive observations; and $\phi$ and $\varphi$ are the standard normal cumulative distribution functions and probability distribution functions respectively.

Tobit model is tested to compare likelihood ratio tests (LR) with results from double hurdle results to determine whether they are significantly different from each other. Additionally, confirm which model is superior on adoption decision. Cragg assumption of independence between error terms in the 1st and 2nd tiers (Vi and Ui). Thus, randomly and independently distributed represented by the following; $\operatorname{Vi} \sim \mathrm{N}(0,1)$ and $\mathrm{Ui} \sim \mathrm{N}\left(0, \sigma^{\wedge} 2\right)$.

On the other hand, the Tobit model is represented as;

$\lambda=\beta / \sigma$ and $X=Z$. 5

According to Greene (2000), the Likelihood Ratio statistic is computed using the following expression:

$\Gamma=-2\left[\ln L_{T}-\left(\ln L_{P}+\ln L_{T R}\right] \sim \chi_{\mathrm{k}}^{2}\right.$. 6

Where L_T - Tobit model likelihood; L_P - Probit model likelihood; L_TR- Truncated Model likelihood; $\mathrm{k}$ independent variables.

\section{STUDY SITE, DATA AND SAMPLING PROCEDURE}

Makueni County is located in the southern part of Eastern Kenya. It lies between Latitude $1^{\circ} 35^{\prime}$, South and Longitude $37^{\circ} 10^{\prime}$ East and $38^{\circ} 30^{\prime}$ East. The county covers an area of $8008.8 \mathrm{Km} 2$. Temperatures ranges between $12{ }^{\circ} \mathrm{C}-28{ }^{\circ} \mathrm{C}$ and bimodal rainfall ranging from $150 \mathrm{~mm}$ to $650 \mathrm{~mm}$ per annum, typical of ASALs in Kenya (RoK, 2013). Low rainfall and temperatures in this county hinder crop production thus livestock production remain a priority. Explicitly, IC production is known for its faster conversion into income generation to meet various family budgets in relation to other livestock. Kakamega county is located in Western Kenya and lies between longitudes $34^{\circ} 32^{\prime \prime}$ and $35^{\circ} 57^{\prime} 30$ East of the prime meridian and latitudes $0^{\circ} 07^{\prime} 30^{\prime \prime}$ North and North $0^{0} 15^{\prime \prime}$ of the equator. It covers total area of $1394.8 \mathrm{Km} 2$. Annual rainfall ranges between 1250 $1750 \mathrm{~mm}$ (RoK, 2010).

Data collection period was collected between March and June, 2015 in Kakamega and Makueni counties in Kenya. A pretested questionnaire was used to conduct structured interviews in Lugari, Shinyalu, Lurambi districts in Kakamega County and, Kaiti, Makueni in
Makueni County. These districts are located in areas that have favourable agro ecological conditions that are required in production of IC and are listed as leading areas in IC production (MoLD, 2011). The county is among others with the highest population of IC raised in rural households (MoLD, 2011). Makueni being an ASAL area was purposively selected for its production potential in poultry. Consequently, adopters and nonadopters of technology were randomly sampled in all the sub counties.

The study applied a stratified random sampling technique in the collection of data from Kakamega and Makueni Counties. The random stratified sampling was preferred since it was able to reduce the biases associated with sampling. This ensured that there was no over presentation or under presentation of the smallholder farmers in the different strata. First, we obtained a list of the sub counties in Makueni and Kakamega counties, which are two counties that are ranked among the leading producers of IC in Kenya. Subsequently, we picked at random Lugari, Shinyalu and Lurambi, from among districts where the IIC had been introduced, within Kakamega County. Further we randomly sampled Makueni and Kaiti from Makueni County. Second, we obtained a list of smallholder farmers from the County Agriculture offices in Kakamega and Makueni counties. Subsequently we obtained a total of 240 households from Kakamega County. This sample size was made of 70 households from Shinyalu, 83 households from Lugari and 87 households from Lurambi. On the other hand, we obtained a total of 144 households from Makueni County. This sample was comprised of 100 households from Makueni District and 44 households from Kaiti District. Consequently, we had a sample of 384 households from Kakamega and Makueni Counties.

The total sample of 384 households includes adopters and non-adopters of IC technology from Kakamega and Makueni County. Therefore, the sample may not be representative of all the IC producing counties in Kenya. However, our sample is representative of the adopters and non-adopters of technology. We obtained data from focus group discussions on other aspects of IIC production in Kakamega and Makueni counties. 
Table 1. Description of dependent and independent variables.

\begin{tabular}{lccc}
\hline Variable & Code & Type & Measurement \\
\hline $\begin{array}{l}\text { Adoption decision on Improved } \\
\text { Indigenous Chicken }\end{array}$ & $\mathrm{D}$ & Dummy & Yes $=1$, No $=0$ \\
$\begin{array}{l}\text { Age of the Household Head } \\
\text { Sex of the Household head }\end{array}$ & AGE & $\begin{array}{c}\text { Continuous } \\
\text { Dummy }\end{array}$ & Years \\
Level of Education Head & SEX & Continuous & Male $=0$, Female $=1$ \\
Farm size & EDUC & Number of years in school \\
Social group & FARMSIZ & Continuous & Acres \\
Type of social group & SOCGRP & Dummy & Yes $=1$, No $=0$ \\
Source of information on IC & TYPESOC & Continuous & Farmer groups $=1$ Others $=0$ \\
Training on poultry production & INFSOU & Continuous & Extension $=1$ Others $=0$ \\
Number of times trained & TRAINPOUT & Dummy & Yes $=1$, No $=0$ \\
Distance to training center & NOTRAIN & Continuous & Number \\
Access to credit & DISTTRAIN & Continuous & Kilometers \\
Other off-farm activities & ACCECRED & Dummy & Yes $=1$, No $=0$ \\
Awareness on IIC & OFFFRMACT & Dummy & Yes $=1$, No $=0$ \\
& AWARONIC & Dummy & If Yes $=1$, No $=0$ \\
\hline
\end{tabular}

\section{RESULTS AND DISCUSSION}

This section presents and discusses the results of the descriptive statistics from the study. Further this section discusses results of the double hurdle models on the decision to adopt and the intensity of adoption of improved indigenous chicken in Makueni and Kakamega counties.

Descriptive statistics: The survey results reveal that approximately $60 \%$ of the sampled households had adopted the improved indigenous chicken (IIC). The mean age of the household head was 47.45 years and out of the sampled households, $72.66 \%$ were headed by male (Table 2). The mean age indicates that few households were headed by youths, who are estimated to have a mean age of 35 years in Kenya, and women hence the IC enterprise was dominated by old and men headed household heads (Republic of Kenya (RoK), 2013). This may be an indicator that IC enterprise needs to be promoted among the youth and women. On the other hand, this result may indicate that IC is an acceptable enterprise among men, who are main decision makers in many households. Results revealed that majority (46.09\%) had attained secondary education and worth noting that a good proportion of respondents had accessed formal education (Table 2). The average household size of the sampled households was 7 members whereas farm size owned by the majority ranged from 1-3 acres. The average mean of the flock size was 81 chickens. On the other hand, majority of the respondents participated in social groups which included farmers group, common interest group (CIG). Chicken production and marketing were main activities by these groups. Farmers in the study area accessed information on indigenous chicken from the extension officers, radios, mobile phones and through internet access. Majority $(85.67 \%)$ of the sampled households had been trained on poultry production. Results also revealed that $31.51 \%$ of the sampled households had access to credit whereas $45.57 \%$ of the sampled households generated incomes from other off-farm activities estimated at an average of Ksh. 16,257 per month.

Econometric model results for the probability of adoption and intensity of improved Indigenous Chicken: The result of the test statistics and $\log$ likelihood values for the probit and truncated model versus the Tobit model are shown on Table 3. The test statistics were used to test the hypothesis related to the use of a double hurdle model versus the use of the Tobit model.

Probit model likelihood $=-219.362$; Truncated Model likelihood $=266.729$ and Tobit model likelihood = 337.215. Thus, the computation was;

$\Gamma=-2[-337.215-(-219.362+266.729)]$

$\Gamma=-2[-384.582]=769.16$

The above test statistics was $\Gamma=769.16$ and above the tabulated value $[\chi \mathrm{k} 2(14)=23.68]$ at a $5 \%$ level of significance. Thus, the double hurdle better fitted the data compared to Tobit Model. This implied that farmer's decision on adoption and the level of adoption of the improved indigenous chicken were made at two separate stages. 
Table 2. Distribution of adopters and non-adopters of Improved IC breeds in both counties.

\begin{tabular}{lccccccc}
\hline \multicolumn{1}{c}{ Variable } & \multicolumn{2}{c}{ Pooled(N=384) } & \multicolumn{2}{c}{ Adopters(N=231) } & \multicolumn{2}{c}{$\begin{array}{c}\text { Non-adopters } \\
\text { (153) }\end{array}$} & \multirow{2}{*}{ P-value } \\
\cline { 1 - 6 } Age & \multicolumn{2}{c}{ Mean } & Std. Err & Mean & Std. Err. & Mean & Std. Err \\
Sex of household head & 47.45 & 0.57 & 47.78 & 0.71 & 46.94 & 0.97 & 0.4752 \\
Level of education & 0.27 & 0.02 & 0.23 & 0.03 & 0.33 & 0.04 & $0.0322^{* *}$ \\
Household size & 2.04 & 0.04 & 2.12 & 0.06 & 1.91 & 0.07 & $0.0201^{* *}$ \\
Size of the farm & 2.72 & 0.04 & 2.75 & 0.06 & 2.69 & 0.07 & 0.4865 \\
Flock size & 2.34 & 0.045 & 2.35 & 0.06 & 2.32 & 0.07 & 0.7073 \\
Social group & 81.60 & 4.33 & 91.74 & 6.06 & 66.30 & 5.68 & $0.0040^{* *}$ \\
Type of social group & 0.82 & 0.02 & 0.91 & 0.02 & 0.68 & 0.04 & $0.0000^{* * *}$ \\
Source of information & 2.12 & 0.10 & 2.46 & 0.13 & 1.60 & 0.14 & $0.0000^{* * *}$ \\
Training on poultry prod. & 9.59 & 0.26 & 9.68 & 0.31 & 9.47 & 0.47 & 0.7056 \\
Number of times trained & 0.86 & 0.02 & 0.94 & 0.02 & 0.74 & 0.036 & $0.0000^{* * *}$ \\
Distance to the centre & 2.89 & 0.09 & 3.16 & 0.10 & 2.48 & 0.16 & $0.0002^{* *}$ \\
Access to credit & 1.96 & 0.07 & 2.27 & 0.08 & 1.49 & 0.10 & $0.0000^{* * *}$ \\
Off-farm activities & 0.32 & 0.02 & 0.39 & 0.03 & 0.20 & 0.03 & $0.0001^{* * *}$ \\
Awareness on IC & 0.46 & 0.03 & 0.49 & 0.032 & 0.41 & 0.04 & 0.1064 \\
\hline
\end{tabular}

Table 3. Test statistics of double hurdle (Probit + Truncated model) versus Tobit model.

\begin{tabular}{lccc}
\hline & Probit, D & Truncated, $Y>0$ & Tobit, $0 \leq \mathrm{Y} \leq 1$ \\
\hline Log likelihood & -219.362 & 266.729 & -337.215 \\
No. of observation & 384 & 231 & 384 \\
Test statistics: $\Gamma=769.53>\chi 20.05,14=23.68$ & & & \\
\hline
\end{tabular}

Factors influencing decision to adopt improved indigenous chicken (IIC): The factors influencing the farmer's decision on adoption and the level of adoption of the improved indigenous chicken are presented in Table 4 and 5. These are the results of the Probit regression, Truncated regression and Tobit regression respectively.

Sex of the household head had a negative effect on probability to adopt the improved indigenous chicken (Table 4). This may indicate that female farmers were more likely to adopt improved IC as compared to their male counterparts. The justification for this is that male participates more in other income generating activities and therefore presuming IC production as an activity that should be carried out by women and children. The variable does not cross to the 2nd hurdle, thus insignificant. The results contradict findings by Doss and Morris (2001) that sex of the household head was insignificant on factors that influenced adoption of improved maize technology in Ghana.

Table 4. Determinants of the decision to adopt improved indigenous chicken technology.

\begin{tabular}{lcccccccc}
\hline & \multicolumn{3}{c}{ Probit } & \multicolumn{4}{c}{ Tobit } \\
\cline { 2 - 9 } & $\begin{array}{c}\text { Marginal } \\
\text { Effect }\end{array}$ & \multicolumn{2}{c}{ Robust } & \multicolumn{3}{c}{ Robust } \\
\cline { 2 - 9 } Improved Indigenous chicken & $\mathrm{dy} / \mathrm{dx}$ & Std. Err. & $\mathrm{Z}$ & $\mathrm{P}>|\mathrm{z}|$ & Coefficient & Std. Err. & $\mathrm{t}$ & $\mathrm{P}>|\mathrm{t}|$ \\
\hline Age of the respondent & -0.0019 & 0.0022 & -0.86 & 0.387 & -0.0049 & 0.0057 & -0.86 & 0.392 \\
Sex of Household head & -0.1114 & 0.0491 & -2.27 & $0.023^{* *}$ & -0.3161 & 0.1244 & -2.54 & $0.011^{* *}$ \\
Level of education & 0.0315 & 0.0282 & 1.12 & 0.263 & 0.0796 & 0.0725 & 1.10 & 0.273 \\
\hline
\end{tabular}




\begin{tabular}{lcccccccc}
\hline Household size & -0.0009 & 0.0275 & -0.03 & 0.974 & -0.0055 & 0.0679 & -0.08 & 0.935 \\
Size of the farm & 0.0540 & 0.0278 & 1.94 & $0.052^{*}$ & 0.1330 & 0.0712 & 1.87 & $0.063^{*}$ \\
Social group & 0.1776 & 0.0773 & 2.30 & $0.022^{* *}$ & 0.3715 & 0.1732 & 2.14 & $0.033^{* *}$ \\
Type of social group & 0.0209 & 0.0144 & 1.45 & 0.147 & 0.0584 & 0.0409 & 1.43 & 0.154 \\
Source of information on IC & 0.0018 & 0.0046 & 0.38 & 0.702 & 0.0010 & 0.0109 & 0.10 & 0.924 \\
Training on poultry production & 0.0150 & 0.1110 & 0.13 & 0.893 & -0.0287 & 0.2463 & -0.12 & 0.907 \\
Number of times trained & 0.0080 & 0.0177 & 0.45 & 0.652 & 0.0204 & 0.0470 & 0.43 & 0.665 \\
Distance to the training centre & 0.0688 & 0.0235 & 2.93 & $0.003^{* *}$ & 0.1923 & 0.0629 & 3.06 & $0.002^{* *}$ \\
Access to credit & 0.0736 & 0.0511 & 1.44 & 0.150 & 0.2169 & 0.1421 & 1.53 & 0.128 \\
Other off-farm activities & 0.0815 & 0.0473 & 1.72 & $0.085^{*}$ & 0.2056 & 0.1195 & 1.72 & $0.086^{*}$ \\
Awareness on IIC & 0.2936 & 0.1513 & 1.94 & $0.052^{* *}$ & 0.5505 & 0.2055 & 2.68 & $0.008^{* *}$ \\
Constant & & & & & -0.5421 & 0.3865 & -1.4 & 0.162 \\
/sigma & & & & & 0.937 & 0.044 & & \\
\hline
\end{tabular}

Source: Own computation; ${ }^{* * *}$ significant at $1 \%$; 88 significant at $5 \%$; significant at $10 \%$; $=384$.

Farm size had significant effect on decision to adopt IIC (Table 4). The results on marginal effect indicates that if the land size increased by one unit (acre) holding other variables constant, the probability of adoption increased by 5 percent. This can be explained by the fact that farmers tend to apportion a relative higher share of the land size in favor of the IIC. Additionally, adoption on IIC doesn't require huge capital to invest on thereby serves as an incentive to allocate more resources on it. The results concurred with Akudugu et al, (2012) where farm size had a positive significance effect on adoption of modern agricultural production technologies by farm households in Ghana. The results also concur with those of Challa \&Tilahun (2014) who found that farm size had a positive effect on the adoption of modern agricultural technology adoption in West Wollega, Ethiopia. However, the result contradicts those of Beshir (2014) where farm size had a negative influence on the decision to adopt improved forages in North East Highlands of Ethiopia. This may show that farmers with large land sizes are likely to diversify into other enterprises apart from IC production.

The results shown on Table 4 indicate that farmer group membership had a positive effect on decision to adopt the IIC. The implications on this result from marginal effect indicate those households that participated in a social group increased the probability of adoption decision by $17.76 \%$ percent while holding other variables constant. The justification is that farmers who participated in a social group are able to access and share information on IIC production, access market information and indulge in collective action especially for those who participated on in those groups whose main activities were IIC production and marketing. The results of this study are consistent with those of Mal et al. (2012) which showed that membership in a club/society positively influenced the decision on adoption of Bt Cotton in North Indian state. This result is unique since unlike other studies on adoption of IIC it shows positive effect of group membership on adoption of IIC.

Distance to the training center was positively and significantly associated with the decision to adopt the IIC (Table 4). The marginal effect indicates that while holding other variables constant, as the distance from the farmers residence to the training centre was increased by one unit (kilometer), the probability of the farmer to adopt IIC increased by $6.95 \%$ percent. This indicates that farmers who lived further from training centers were more likely to adopt IIC compared to those who lived closer to training centers. This result may indicate a need for innovative approaches such as mobile training centers, which are likely to improve on the adoption of IIC among smallholder farmers. The results are consistent with those studies that show relationship between technology adoption and infrastructure, which is proxy by distance to training centers (Cornell, 2010).

On the other hand, other off farm activities passed the first hurdle and positively affected the decision to adopt IIC (Table 4). Farmers who had adopted the IIC were endowed with additional sources of income from the non-farm activities thereby being in a prospect to purchase the improved indigenous chicken. The 
coefficient implied that by holding other variables constant, the probability of making the decision to adopt the improved indigenous chicken. Therefore, by having incomes apart from the on farm activities, there is a strong positive role on the decision of the household adopting the technologies. This finding was consistent with the results of Beshir et al. (2012) that revealed that the availability of off-farm income had a positive significant effect on adoption of technology. The results controvert findings of Akudugu et al. (2012) that off farm activities negatively affected adoption decision of modern agricultural production technologies by farm households in Ghana.

Awareness on IIC affected the decision to adopt IIC technology (Table 4). The justification for this is that farmers who heard or have read on IIC are more likely to adopt compared to those who have not. To increase productivity of the IC in order to sustain the livelihood of the poor rural households, farmers are accessing education of IIC through trainings by the extension officers, service providers among other stakeholders. Awareness on IIC had positive impact on both the decision to adopt and also the level of adoption. The results of this study are consistent with those of Tambo
\& Abdoulaye (2011) who found that climate change awareness was significant and positively influenced both the decision and the level of adoption of drought tolerant maize in rural Nigeria.

Determinants of the IIC adoption intensity: Education of the households significantly affects the intensity of adoption of the IIC (Table 5). An increase in years of education by one year increased the intensity of adoption by $23 \%$ holding all other factors constant. The implication for this is that an educated farmer is willing to embrace new technologies and allocate more resources on information access regarding the IIC derived from various sources such as; workshops, seminars, television, radio, internet among other sources. They turn out more efficient and able to evaluate and interpret information about innovation compared to those with less education.

The results are consistent with those of Tambo and Abdoulaye (2011) that showed positive and significant relationship of education and intensity of drought tolerant maize in rural Nigeria. However, the results contradict with findings by Ibitoye (2011) where education was significant and positively influenced decision to adopt improved cassava technologies in Nigeria.

Table 5. Truncated Model for the intensity of adoption of the improved indigenous chicken.

\begin{tabular}{|c|c|c|c|c|}
\hline \multirow{2}{*}{ Improved indigenous chicken } & \multicolumn{3}{|c|}{ Robust } & \multirow[b]{2}{*}{$\mathrm{P}>|\mathrm{z}|$} \\
\hline & Coefficient & Std. Err. & $\mathrm{Z}$ & \\
\hline Age of the respondent & 0.0014 & 0.0009 & 1.63 & 0.104 \\
\hline Sex of Household head & 0.0160 & 0.0129 & 1.24 & 0.214 \\
\hline Level of education & 0.0233 & 0.0116 & 2.01 & $0.044^{* *}$ \\
\hline Household size & 0.0206 & 0.0110 & 1.86 & $0.062^{*}$ \\
\hline Size of the farm & 0.0219 & 0.0109 & 2.01 & $0.045^{* *}$ \\
\hline Social group & 0.0397 & 0.0265 & 1.5 & 0.135 \\
\hline Type of social group & -0.0002 & 0.0016 & -0.15 & 0.882 \\
\hline Source of information on IC & 0.0054 & 0.0028 & 1.95 & $0.052^{*}$ \\
\hline Training on poultry production & 0.0398 & 0.0431 & 0.92 & 0.356 \\
\hline Number of times trained & 0.0018 & 0.0028 & 0.64 & 0.519 \\
\hline Distance to the training centre & -0.0030 & 0.0038 & -0.8 & 0.424 \\
\hline Access to credit & -0.0081 & 0.0072 & -1.13 & 0.257 \\
\hline Other off-farm activities & 0.0055 & 0.0106 & 0.51 & 0.607 \\
\hline Awareness on IIC & 0.6493 & 0.1679 & 3.87 & $0.000^{* * *}$ \\
\hline
\end{tabular}

Source: Own computation ${ }^{* * *}$ significant at $1 \%,{ }^{* *}$ significant at $5 \%,{ }^{*}$ significant at $10 \%$; $=384$.

The household size had a positive effect on the intensity of adoption as shown in Table 5. An increase in the family size by one member increased the intensity of adoption by $21 \%$ (percent). This implied that the household members were more likely to allocate more labor and concerns towards the IIC production as 
compared to other on-farm livestock practices. The results contradict the findings of Beshir (2014) which revealed a negative influence of household size on the level of use of improved forages in North-East Highlands of Ethiopia. However, the results are consistent with Ayieko et al. (2014) who identified that the household size positively influenced the number of indigenous chickens sold to high value markets among the smallholder farmers in Makueni County.

Source of information about IIC production had a positive effect on the level of IIC adoption although insignificant in influencing decision to adopt (Table 5). Those who had access to source of information on IC increased the intensity of adoption by 5\% (percent). This may be explained by diverse IIC production trainings, workshops and seminars by the extension officers, service providers among other poultry production stakeholders. This is an implication that increased extension contacts impacts positively on the level of adoption of IIC. However, this contradicts results by Tambo \& Abdoulaye (2012) where sources of information were insignificant on influencing intensity to adopt the drought resistance maize in Nigeria.

Awareness on IIC affected the intensity of adopting IIC technology (Table 5). Awareness of IIC lead to an increase in the intensity of adoption by $65 \%$ (percent). Those households that were aware of IIC knew the potential benefits (income, food security among others) of adopting IIC and hence had a higher intensity of adopting IIC. The results of this study are consistent with those of Tambo and Abdoulaye (2011) who found that climate change awareness was significant and positively influenced both the decision and the level of adoption of drought tolerant maize in rural Nigeria.

\section{CONCLUSION AND RECOMMENDATIONS}

The study analyzed the determinants of adopting IIC technology and the intensity of adopting IIC technology. The decision to adopt IIC technology and the intensity of adopting IIC was significantly influenced by a range of socioeconomic characteristics. The results showed that sex of household head, size of farm, participation in social group, distance to training center, off farm activity and awareness of IIC significantly influenced the decision to adopt IIC. On the other hand the intensity of adopting IIC technology was significantly influenced by education level of household head, household size, size of farm, source of information and awareness of IIC technology. The results of the study have shown consistency with those of studies done in determinants of adoption and intensity of technology adoption among the smallholder farmers.

The theoretical and empirical approaches that were adopted by this study produced satisfactory results. These results can be used in understanding the factors that underlie the adoption and the intensity of adopting IIC technologies in the context of smallholder farmers. Moreover, the study included awareness, group membership, off farm activities, distance to training center and source of information on IIC in analysis of adoption and intensity of adoption. Further the study showed that the adoption and intensity stages are made successively which concurred with previous studies.

Sex of household heads had a significant effect on the decision to adopt IIC technology. However, the results showed women headed households were more likely to adopt IIC technology compared to the male headed households. The meaning of this is that more men should be targeted when promoting IIC technology. Moreover, promotion of IIC technology should be aware of gender issues as a factor in the adoption and intensity of adoption of IIC technology. Promoters of IIC should therefore focus on the women groups as viable channels for promotion of IIC technologies. Moreover, policy interventions should address the adoption of IIC through women groups.

Size of farm has significant effect on the adoption and intensity of adoption of IIC technology. This means that access to land will increase the adoption of IIC technologies by adopters. However, in some cases where access to land may not be possible other options of land ownership such as leasing could be exploited. Therefore, this has policy implication in terms of the land use rights and tenancy for smallholder farmers.

The IIC are more likely to be adopted within larger households compared to smaller households. Therefore, we concluded that IIC technology, which include improved chicken breeds, are a potential source of food security for larger households. Therefore, policy on food security should consider IIC technology, including improved IC breeds, as a potential food security for households in ASALs.

Households that are headed by individuals with higher education levels are more likely to increase the intensity of adopting IIC technology. This shows the importance of capacity building on increasing intensity of adopting IIC technology. Therefore, there is potential of incorporating 
IIC technology into current education content in the ASALs. Moreover, policy on agriculture education could consider incorporating IIC technology into current curriculum.

The current extension source of information on IC has a positive influence on the intensity of IIC technology adoption. The use of extension as a channel of information appears to be effective on increasing on the intensity of adopting IIC technology. Therefore, extension policy should enhance current extension approaches by incorporating different measures.

Distance to training centers has a positive effect on decision to adapt IIC technology in ASAL areas. Consequently, there is a potential of introducing mobile training centers or onsite training centers away from training centers. This indicates that policy on agriculture extension may focus on introduction of innovative training methods such as on site or mobile training centers in ASAL areas.

Off farm activities have a positive effect on decision to adapt IIC in ASALs. Consequently, there is need to encourage diversity in off farm activities which generate income to supplement on the adoption of IIC technology. This may indicate that the current IIC technologies are perceived to be expensive and hence are adopted by household with sufficient resources. Therefore, there is a need for policy to focus on introduction of affordable IIC technologies in ASAL areas. Alternative policy focus should be aimed at reducing the prices of current IIC technologies through subsidies or cost cutting measure in the production to make them affordable to smallholder in ASALs.

There was a significant influence of participation in social group and awareness of IIC on adoption of IIC technology. This result is significant since among all studies that were reviewed on adoption of IIC none showed significant effects of social groups on adoption of IIC. However, this study has established the effect of social groups on adoption of IIC. Therefore, Social group can be considered an avenue for creating awareness on IIC among smallholder households. Hence, policy on extension should focus on using social groups for promotion of IIC among smallholders in Kenya.

The findings of this study provide policy options to policy makers in terms of IIC technology adoption and the intensity of adoption. Therefore, the policy makers are able to know which socioeconomic factors have a significant influence on the adoption of IIC technologies.
The policy makers can therefore consider these factors to improve on the current adoption levels of IIC in Kakamega and Makueni counties. However, this is not a conclusion of the impact of the same factors on adoption. The impact of the factors on adoption IIC is beyond the scope of this study. Therefore, this study has been able to inform on the determinants of the adoption of IIC and the intensity of adoption of IIC technology. Hence, we have opened up possibilities of further research on the adoption of IIC on smallholder farmer welfare.

\section{ACKNOWLEDGEMENT}

We acknowledge support from the World Bank through the Kenya Agricultural Productivity and Agribusiness Projects in collaboration with Indigenous Chicken Value Chain (ICVC) project implemented under Kenyatta University.

\section{REFERENCES}

Abreha, N. H. (2007). An Economic Analysis of Farmers' Risk Attitudes and Farm Households' Responses to Rainfall Risk in Tigray Northern Ethiopia. Hoogleraar Agrarische Economie en Plattelandsbeleid (Vol. PhD).

Aboki, E., Jongur, A.A.U. \& Onu, J.I. (2013). Productivity and Technical Efficiency of Family poultry production in Kurmi local Government Area of Taraba State, Nigeria. Journal of Agriculture \& Sustainability, 4 (1).

Adomako, K., Hagan, J.K. \& Olympia, O.S. (2010). The productivity of local chickens in the Ashanti Region of Ghana. Ghananian Journal of Animal Science, 5 (2), 113 - 118.

Adesina, A. Baidu.-Forson. (1995). Farmers' perceptions and adoption of new agricultural technology: evidence from analysis in Burkina Faso and Guinea, West Africa. Agricultural Economics, 13, 19.

Adesina, A. \& Zimnah, M (1993). Technology characteristics, farmers' perceptions and adoption decisions: A Tobit model application in Sierra Leone. Agricultural Economics, 297-311.

Akudugu, M., Guo, E., Dadzie, S. (2012) Adoption of Modern Agricultural Production Technologies by Farm Households in Ghana: What Factors Influence their Decisions? Journal of Biology, Agriculture and Healthcare 2(3).

Arnholt, M. (2001). Evaluating Adoption and Uses of Precision Farming Technologies. A Thesis Presented in Partial Fulfillment of the 
Requirements for the Degree Master of Agricultural, Environmental, and Development Economics in the Graduate School of The Ohio State University. Ohio, USA: Ohio State University.

Asrat, S.M. Y. (2010). Farmers' preferences for crop variety traits: Lessons for on-farm conservation and technology adoption. Ecological Economics, 2394-2401.

Awol Zeberga. (2010). Analysis of Poultry Market Chain: The Case of Dale and Alaba 'Special" Woredas of SNNPRS, Ethiopia. Haramaya University.

Awuni. J.A. (2003). Strategies for the improvement of Rural Chicken production in Ghana. 34 - 37.

Ayieko, D.M.O., Bett, E.K. \& Kabuage, L.W. (2014). Analysis of the efficiency of Indigenous Chicken marketing channels in Makueni County, Kenya. Journal of Economics \& Sustainable Development, 3 (2).

Bett, H.K., Peters, K., Nwankwo, U. \& W. Bokelmann. (2011, October). Estimating consumer preference \& willingness to pay for the underutilized indigenous chicken products.

Beshir,H. (2014). Factors affecting the adoption and intensity of use of improved forages in North East Highlands of Ethiopia. American Journal of Experimental Agriculture, 4 (1), 12 -27.

Bwalya,R \& Thomson,.K. (2014). An Analysis of the Value Chain for Indigenous Chicken in Zambia,Lusaka and Central Provinces. Journal of Agricultural studies, 2 (2), 32-49.

Challa,M \& Tilahun,U (2014). Determinants and impacts of Modern Agricultural Technology Adoption in West Wollega: The case of Gulliso District. Journal of Biology, Agriculture and Healthcare, 4 (20).

Chi, T.C.C \& Yamada,R (2002). Factors affecting farmers' adoption of technologies in farming system: A case study in OMon district, Can Tho province,Mekong Delta. Omonrice , 10, 94-100.

Cornell, A. (2010). Small actor, big opinion: Least Developed Countries participation in climate change networks. Procedia - Social and Behavioral Sciences, 4, 59-70.

Cragg, J. (1971). Some statistical models for limited dependent variables with application to the demand for. Econometrica, 39, 829-844.

Demeke, E. T. (2015). Characterization of Husbandry Practices,Adoption and Impact of Village Poultry Technology Packages in Central Oromia
Region,Etthiopia. A Dissertation Submitted to College of Veterinary Medicine and Agriculture, Addis Ababa University for Fulfillment of the Requirement of Degree of Doctor of Philosophy in Animal Production.

Dana, N. (2011). Breeding programs for indigenous chicken in Ethiopia Analysis of diversity in production systems and chicken populations. Wagingen University.

Doss, C.R \& Morris, M.L. (2001). How does gender affect the adoption of agricultural innovation? The case of improved maize technologies in Ghana. Journal of Agricultural Economics, 25, 27-39.

Ectad (FAO). (2009). Good practices in small scale poultry production: A manual for trainers and producers in East Africa, 99. Retrieved from http://www.fao-ectadnairobi.org/IMG/pdf/Poultry_Manual_for_Trainer s_and_Producers.pdf

Epiphane Sodjinou, A. H. (2012). Community-Based Management and Interrelations between Different Technology Adoption Decisions: Innovations in Village Poultry Farming in Western Africa. Institute of Food and Resource Economics University of Copenhagen FOI Working Paper .

Ezezika, O. C., Mabeya, J., \& Daar, A S. (2012). Harmonized biosafety regulations are key to trust building in regional agbiotech partnerships: the case of the Bt cotton project in East Africa. Agriculture and Food Security, 1(Suppl. 1), S8. https://doi.org/10.1186/2048-7010-1-S1-S8

Food and Agriculture Organization(FAO). (2015). Food security impact of agricultural technology adoption under climate change Micro-evidence from Niger. Rome: Food And Agriculture Organization Of The United Nations.

FAO (Food and Agriculture Organization of the United Nations). (2012). Small Livestock, big impacts. Retrieved october 5, 2014, from http: //www.fao.com

FA0. (2012). Small livestock, big impact. Retrieved February 3, 2015, from http://ilriclippings.wordpress.com.

FAO, ECTAD. (2009). Good Practices in Small scale poultry production. A manual for Trainers and procedures in E. Africa.

Fisher, D. N. (2000). Understanding technology adoption through system dynamics modeling: implications 
for agribusiness management. International Food and Agribusiness Management Review, 3,281296.

Ghimire, R. Wen, C. H., Shrestha, R. (2015). Factors Affecting Adoption of Improved Rice Varieties among Rural Farm Households in Central Nepal. Rice Science, 22(1): 35-43.

Gillespie, J. N. (2014). The adoption of technologies, management practices, and production systems in U.S. milk production. Agricultural and Food Economics, 2,17.

GOK. (2007). Kenya Integrated Household Budget Survey. Government of Kenya, Nairobi, Kenya.

Greene, W.H. (2000). Econometrics analysis (4th Edition).

Heckman, J.J. (1979). Sample bias as a specification Error, Econometrica (Vol. 47 (1)).

Hossen, M.J. (2010). Effect of management intervention on the productivity and profitability of indigenous chicken under rural condition in Bangladesh. Livestock Research for Rural Development, 22 (10).

Ibitoye, S.J. (2011). The influence of socio-economic variables on the choice of Cassava varieties in Kogi State. International Journal of Agricultural Sciences, 185-193.

Kahi, A.K., Magothe, T.M., Okeno, T.O. \& Muhuyi, W.B. (2012). Indigenous Chicken Production in Kenya. Prospects of Research adn Development. (A. Kahi, Ed.)

Kandia, J.. \& Kitalyi, A.J. (2002). Commercializing rearing of village chicken in Kenya.

KARI. (2011). Kenya Agricultural Research Institute Annual Report.

Kidanemariam, G.E., Erick, M., Jozef, D., Kindeya, G., Hans, B. \& Miet, M. (2013). The Economic Impact of a New Rural Extension Approach in N.Ethiopia. Working Paper, Bioeconomics, Ethiopia.

King'ori, A., Wachira, A. \& Tuitoek, J. (2010). Indigenous Chicken production in Kenya. International Journal of Poultry Science, 9 (4).

King'ori, A.M., Wachira, A.M., \& Tuitoek, J.K. (2010). Indigenous Chicken Production in Kenya. A review, International Journal of Poultry Science, 9 (4), 309 - 316.

Magothe, T., Okeno, T., Muhuyi, W., \& Kahi, A. (2012). Indigenous chicken production in Kenya: II. Prospects for research and development. World's
Poultry Science Journal, 68, 133-144.

Kummar,R.D., M.I. Saiful., Ashraful, K. (2013). Production performance of Indigenous Chicken (Gallus Domesticus L.) in some selected areas of Rajshahi, Bangladesh. (M. S. R.Kummar Dutta, Ed.) American journal of Experimenntal Agriculture, 3 (2), 308323.

Lyimo, H. E. (2013). Impact of Adoption of Local Improved Chicken production methods in Tanzania: Case Study of Umadep and ILRP SUA projects. A thesis, Master of Science in Management of Natural Resources, Sokoine University of Agriculture Morogoro Tanzania.

Magothe, T.M., Okeno, T.O., Muhuyi, W. \& Kahi, A.K. (2012). Indigenous Chicken production in Kenya: 1. Current Status. Worlds poultry Science Journal, 119-132.

Mal, P.A.,Asif, R.A., Bauer, S. \& Michael, P. S. (2012). Bt Cotton Adoption: A Double-hurdle Approach for North Indian farmers. 15 (3), 294 - 302.

Mapiye, C.M., Mwale, J.F., Mupangwa, M., Chimonya, R \& Mutenje, M.J. (2008). A Research Review of Village chicken production constraints and opportunities in Zimbabwe. Asia- Australian Association of Animal Production Societes, 21 (11), 1680 -1688.

Masha, E. M. (2011). Assessment of Technology Adoption for free range local chicken improvement in local chicken improvement in Mzumbe ward Mvomero District Morogoro. A dissertation presented in Partial fulfilment of requirements of Degree of Master of Science in Tropical Animal production of Sokoine University of Agriculture. Morogoro, Tanzania.

Menge, E.O., Kosgey, I.S. \& Kahi, A.K. (2005). Bioeconomical Model to support breeding of Indigenous Chicken in different production systems. International Journal of Poultry Science, 4 (11).

Mengesha, M. (2012). Indigenous Chicken production \& the innate characteristics. Asian Journal of Poultry Science, 6 (2), 56 - 64.

Mc Fadden, D. (2001). Economic Choices. The American Economic Review, 91,3, 351-378.

Ministry of Livestock and Fisheries Development. (MoLD) (2011). Animal production Annual Report. Nairobi, Kenya.

Moreki, J., Dikeme, C. \& Poroga, B. (2010). The Role of Village Poultry in food security and HIV/AIDS 
mitigation in Chobe District of Botswana. Livestock Resurces for Rural Development (22).

Njue, S. K. (2006). Assessing the economic impact of commercial poultry feeds supplementation and Vaccination against New Castle Disease in local chicken in Kenya. Proceedings of a Final Research coordination meeting organized by Joint FAO \& IAEA. Viena.

Ochieng,J., George, O., Bockline, O.M. (2011). Management practices and challenges in Smallholder indigenous Chicken production in western Kenya. Journal of Agriculture \& Rural Development in the Tropics and Sub-tropics, 1 (114).

Okello, J.J., Gitonga, Z., Mutune, J., Okello, R.M., Afande, M. \& Rich, K.M. (2010). Value Chain Analysis of the Kenyan poultry industry. The case of Kiambu, Kilifi, Vihiga and Nakuru Districts. HPAI Working Paper 24, Washington D.C.

Okello, J.J., Gitonga, Z., Mutune, J., Okelo, R.M., Afande, M. \& Rich, K.M. (2010). Value Chain Analysis of the Kenyan poultry Industry. Kenya.

Lambert, D. P. (2015). Bundled Adoption of Precision Agriculture Technologies by Cotton Producers. Journal of Agricultural and Resource Economics, $40(2), 325-345$.

Mendola, M. (2007). Agricultural technology adoption and poverty reduction: A propensity-score matching analysis for rural Bangladesh. Food Policy , 32,372-393.

Muzari, W. G. (2012). The Impacts of Technology Adoption on Smallholder Agricultural Productivity in Sub-Saharan Africa: A Review. Journal of Sustainable Development, 5, 8, 69-77.

Abreha, N. H. (2007). An Economic Analysis of Farmers' Risk Attitudes and Farm Households' Responses to Rainfall Risk in Tigray Northern Ethiopia. Hoogleraar Agrarische Economie en Plattelandsbeleid (Vol. PhD).

Awol Zeberga. (2010). Analysis of Poultry Market Chain:The Case of Dale and Alaba 'Special" Woredas of SNNPRS,Ethiopia. Haramaya University.

Cornell, A. (2010). Small actor, big opinion: Least Developed Countries participation in climate change networks. Procedia - Social and Behavioral Sciences, 4, 59-70.

Dana, N. (2011). Breeding programs for indigenous chicken in Ethiopia Analysis of diversity in production systems and chicken populations. Wagingen University.

Ectad (FAO). (2009). Good practices in small scale poultry production: A manual for trainers and producers in East Africa, 99. Retrieved from http://www.fao-ectadnairobi.org/IMG/pdf/Poultry_Manual_for_Trainer s_and_Producers.pdf

Ezezika, 0. C., Mabeya, J., \& Daar, A S. (2012). Harmonized biosafety regulations are key to trust building in regional agbiotech partnerships: the case of the Bt cotton project in East Africa. Agriculture and Food Security, 1(Suppl. 1), S8. https://doi.org/10.1186/2048-7010-1-S1-S8

Kingori, A. M., Wachira, a. M., \& Tuitoek, J. K. (2010). Indigenous chicken production in Kenya: A review. International Journal of Poultry Science, 9(4), 309-316.

Magothe, T., Okeno, T., Muhuyi, W., \& Kahi, A. (2012). Indigenous chicken production in Kenya: II. Prospects for research and development. World's Poultry Science Journal, 68 , 133-144.

Republic of Kenya (RoK). (2013). Kenya Economic Report 2013. Nairobi.

Sodjinou, E., \& Henningsen, A. (2012). Community-Based Management and Interrelations between Different Technology Adoption Decisions: Innovations in Village Poultry Farming in Western Africa Epiphane Sodjinou.

Thiruvenkadan.A.K., Muralidharan., Rajendran.R., S. (2013). Genetic Resources for family poultry production in India. Journal of Chemical Information and Modeling, 53(9), 1689-1699.

ROK. (2010). Agricultural Sector Development Strategy. Nairobi.

ROK. (2007). Kenya Integrated Household Budget Survey. Government of Kenya, Nairobi,Kenya.

Sadya A.M.A. (2012). Family Poultry as a tool in alleviating environmental hazards in settled areas of Transhumant families in Gezira Scheme, Sudan. Asian Journal for Rural Development, 2, 1-12.

Safalaoh, A. (2012). Pro-poor Innovations? Determinants of Adoption of the Black Australorp Chicken Breed and Application of the Innovation Platform Concept in Malawi1. Paper presented at the 8th International $\mathrm{PhD}$ School on Innovation and Economic Development: Globelics Academy 2012, 
Rio de Janeiro, Brazil, 20-31 August, 2012.

Shakya, P.B. \& Flinn, J.C. (1985). Adoption of modern varieties and fertilizers use on rice i the Eastern Tarai of Nepal. Journal on Agricultural Economics. 36 (3).

Tambo,A.J \& Abdoulaye,T (2012). Climate Change and agricultural technology Adoption: The Case of drought tolerant maize in Rural Nigeria. Mitig Adapt Strateg Global Change.

Teklewold, H., Dadi, L., Yami A. \& Dana N. (2006). Determinants of adoption of poultry technology: a doublehurdle. Livestock Research for Rural Development Volume, 18.

Thiruvenkadan.A.K., Muralidharan., Rajendran.R., S. (2013). Genetic Resources for family poultry production in India. Journal of Chemical Information and Modeling, 53(9), 1689-1699.

USAID. (2010). Value chain Analysis of poultry. Partnership for safe poultry in Kenya (PSPK) Program.

Wachira, M.A, S.K.Mail. (2010). Uptake of improved technologies through disemmination by
Indigenous chicken service providers in Southern Rangelands of Kenya.

Wanjugu, N. P. (2013). The factors Influencing Indigenous poultry production in Kathiani District,Machakos County,Kenya. A Research project submitted in Partial fulfilment of the requirement of the Award of the Degree of Master of Arts in Project planning and Management of the University of Nairobi.

Winter, P., Salazar, L. \& Mafifioli, A. (2010). Designing Impact evaluations for agricultural projects. Stratecy Development Division, Inter-American Developmnet bank, Washington DC.

Wooldridge, J. 2002. Econometric Analysis of Cross Section and Panel Data. The MIT Press, Cambridge, Massachusetts, USA.

World Society for the Protection of Animals (WSPA). (2012). Livestock Production and Climate Change.

Yitbarek, M.B. \& Andargie, Z. (2013). Performance Evaluation of Local Chicken at Enebsie, Sar Middir, Eastern Gojjam, Ethiopia. World Research Journal of Agricultural Sciences \& Technology, 1 (1). 